\title{
An Experimental Examination of Labor Supply and Work Intensities
}

\author{
David L. Dickinson, Utab State University
}

\begin{abstract}
Estimated negative substitution effects on work hours question the empirical validity of the classical labor supply model. Estimates are reconciled by allowing a dual choice of hours and effort for piecerate workers. In such a model, these negative substitution effects result from substituting on- and off-the-job leisure. We test our model using controlled experimentation on human subjects. These experiments, while not naturally occurring environments, represent real economic choices and can generate data unavailable elsewhere (e.g., effort data). The results support our model, and they have implications both for labor management and for empirical research focusing only on the hours choice.
\end{abstract}

The classical static model of the labor-leisure choice offers positive compensated wage effects on hours of work as its main testable implication. Previous attempts to test this hypothesis with field data have cast doubt on the empirical validity of the static labor supply model due to the frequency of negative estimated compensated wage elasticities. A limitation of the model is that it views the choice of hours of work as the only

I would like to thank Jim Cox, Ron Oaxaca, Leslie Stratton, Price Fishback, Devajyoti Ghose, and Mary-Anne Sillamaa for many helpful comments. I would also like to thank the participants of the Economic Science Association conference as well as those of the Experimental Economics seminars and workshops at the University of Arizona for their valuable comments. Finally, I thank the Economic Science Laboratory and the Department of Economics at the University of Arizona, and the Olin Foundation for funding the experiments for this article. Address correspondence to the author at the Department of Economics, Utah State University, 3530 Old Main Hill, Logan, UT 84322-3530. All errors in this article are my own responsibility.

[Journal of Labor Economics, 1999, vol. 17, no. 4, pt. 1]

(C) 1999 by The University of Chicago. All rights reserved.

0734-306X/1999/1704-0007\$02.50 
margin of interest, when in fact many workers make calculated decisions about the intensity or effort with which they work.

This article examines two extensions of the static model. In one model, hours of work are fixed while work effort is the choice variable, and in the other model workers choose both hours of work and work effort. These models admit the consumption of on-the-job leisure by allowing work effort to vary: a type of leisure not included in the classical theory. In both models workers earn piece-rate wages. In the first model (where workers choose effort), the testable implication is that income-compensated wage increases will increase work effort. In the second model (where workers choose both effort and hours of work), income-compensated wage increases may actually decrease hours of work under the plausible assumption that workers substitute on- and off-the-job leisure. It is this possibility of theoretical negative substitution effects on hours worked with piece-rate wages that motivates a test of the implications of the model.

Both models are tested (in Sec. IV) using controlled laboratory experimentation on human subject workers. In general, there are always benefits and drawbacks to a specific methodological approach. One drawback in using controlled experimentation for theory testing is that the data sets are usually smaller than field experiment or survey data sets. Also, the fact that individuals are not participating in the "naturally occurring" economic environments we wish to study may question our ability to extend experimental results to other settings.

However, the benefits (at least for certain types of studies) are impressive. The controlled setting of the experiments greatly reduces the variables that may be confounding the results derived from data generated in more uncontrolled settings. Also, for this particular study, there exists no naturally occurring data set that provides the sufficient level of information on both hours of work and work effort. Such data could possibly be generated, but it is not clear how unbiased data on work effort could be acquired (along with work hours data), and the cost could be quite high. For the purpose of comparison, a single wave of the Current Population Survey (CPS) costs roughly $\$ 34$ per observation, which is slightly higher than the approximate $\$ 24$ per observation cost of these experiments. ${ }^{1}$ In addition to higher per observation costs, one wave of the CPS does not yield detailed data on work effort and must also rely on unbiased reporting by participants. The experiments reported in this article elicit actual

${ }^{1}$ Of this, field costs are approximately $\$ 25$ per person. Figures are from the U.S. Census Bureau and are all meant to be interpreted with caution as they do contain "noise." The figure ( $\$ 34$ per observation) is basically the CPS's total annual operating costs divided by the number of annual surveys. These figures do not include any CPS start-up costs. 
labor-leisure behavioral responses and include the detailed data on work effort needed for this study.

It is also fair to note that one wave of the CPS (or the Panel Study for Income Dynamics [PSID], or the National Longitudinal Survey of Youth [NLSY], etc.) is an ongoing survey, whereas the experiments in this article were completed in a short period of time. A comparison with a more ambitious field study, the Negative Income Tax (NIT) experiments, shows how truly expensive a complete field experiment can be. The cost of the NIT experiments was roughly $\$ 338$ million (1996 dollars). The experiments presented in this article cost about $\$ 3,000$ in 1996 . While admittedly a much smaller data set, the per person cost is still most economical-about $\$ 73$ per person compared to $\$ 23,488$ per person for the NIT experiments. ${ }^{2}$ Furthermore, subjects in these controlled laboratory experiments participate in an economic environment that is meaningful because of the monetary payments that are tied directly to their decisions. Such environments can be tailor-made to collect the type of data needed for a particular study, and, as we have seen, these experiments are cost effective. In general, experimentally collected data should be viewed as a complement to survey and field data, not a substitute. To address the issues discussed in this article, however, any data collected must contain sufficient information on both hours worked and work effort.

The results of this study show that when hours of work are not a choice variable-a possibility that describes many short-run labor supply decisions-work effort on the job decreases, given an income-compensated wage decrease (in 11 of 15 cases), thereby supporting the first extension of the model. This has obvious implications (on worker effort levels) for managers who may alter wages and the nonwage compensation of their work force. When both work effort and hours of work are a choice variable, eight of 26 subjects display negative substitution effects on hours of work. These are not estimated effects but, rather, observed substitution effects from a wage change that is decomposed across multiple experimental work days. Such results support the extended model of laborleisure choice and imply that future studies should recognize on-the-job leisure whenever possible. Moreover, existing studies with estimated negative

2 This figure is based on a total of 8,746 families enrolled in the four NIT experiments reported in Robins (1985). Families other than single-headed families consisted of two individuals (husband and wife) and are counted as such since both husband and wife data are exploited in the data analysis of the NIT experiments. Even if one eliminates the administrative costs and focuses only on direct subject payments, the NIT experiments averaged \$6,583 per person in 1996 dollars. 
substitution effects on hours worked may consider exploring these on-thejob leisure implications of piece-rate paid workers in their data.

\section{Previous Studies of the Labor-Leisure Decision}

Typical empirical studies have estimated equations of the form $\partial h / \partial w$ $=\left.(\partial h / \partial w)\right|_{m=\bar{m}}+b(\partial h / \partial m)$, where $b$ is hours of work, $w$ is an hourly wage, and $m$ is income. This is the typical Slutsky equation that decomposes the wage change into a substitution and an income effect. Multiplying through by $w / h$ gives us the elasticity version of the equation that can be concisely written as $\eta=\eta_{s}+(w h / m) \cdot \eta_{b, m}$ where $\eta$ is the uncompensated wage elasticity, $\eta_{S}$ is the compensated wage elasticity (theoretically predicted to be positive), and $(w h / m) \cdot \eta_{b, m}$ is referred to as the total income elasticity. Surveys of empirical studies in Pencavel (1986) and Killingsworth and Heckman (1986) look at the labor supply of men and women, respectively. Estimation of $\eta_{s}$ for men from U.S. and British nonexperimental data show $\eta_{S}$ is estimated to be positive mostly, with an average estimate of less than .30 . Estimated compensated wage elasticities are positive and slightly higher when using experimental data from the NIT experiments. ${ }^{3}$ There is also a tendency for $\eta>0$, implying positively sloped labor supply functions. One cannot help but notice, however, the number of negative estimates of $\eta_{s}$ in existing studies. ${ }^{4}$ These estimates violate the key prediction of the static labor supply model. The same basic conclusion with respect to estimated values of $\eta_{S}$ is found in Killingsworth and Heckman's survey of female labor supply. They report mostly positive estimates of $\eta_{s}$ and $\eta$ with some notable exceptions. It is the quantity of negative estimates of $\eta_{S}$ that casts doubt on the empirical validity of the static labor supply model.

Other empirical studies involve less standard data sets. ${ }^{5}$ Battalio et al. (1981) and Battalio, Green, and Kagel (1981) test the static labor supply model using pigeons and find positive compensated wage effects in general. Their experiments represent a very controlled test of the theory and,

${ }^{3}$ The reader interested in a detailed discussion of field labor supply experiments and their statistical analysis is directed to Spiegelman and Yaeger (1980), Moffit and Kenhrer (1981), and Robins (1985).

${ }^{4}$ Examples of studies which yield negative estimates of $\eta_{s}$ include Atkinson and Stern (1980) and Ham (1982) on male labor supply, and Nakamura and Nakamura (1981) and Robinson and Tomes (1985) on female labor supply.

${ }^{5}$ Some creative field studies address the labor supply issue but do not decompose the wage change. Camerer et al. (1997) estimated uncompensated wage elasticities of New York City cab drivers. Other studies use laboratory experimentation to study rat labor supply using ethanol solution as payments (Collier and Jennings [1969]; Collier, Hirsch, and Hamlin [1972]; and Meisch and Thompson [1972, 1973]). Still others use human subjects with alcohol (Bigelow and Liebson [1972]) or nicotine reinforcements (Bickel et al. [1991]). 
although not standard in their use of nonhuman subjects, are not subject to some of the experimental criticisms of the NIT experiments (e.g., the nonrandom subject/treatment assignments implicit in choosing only rural or low-income populations for some treatments). Consistent with other empirical studies, they also observe a backward-bending labor supply curve at higher wages. Nonetheless, a limitation of these laboratory and empirical studies is that they do not examine the labor-leisure choice while allowing workers to choose both hours of work and work effort-a choice that is clearly possible in work settings in which hours of work are chosen.

Work effort has been examined mainly at the theoretical level in efficiency wage models. ${ }^{6}$ A survey by Yellen (1984) presents the relevance of such models in explaining involuntary unemployment and other stylized labor market facts. In such models, work effort is typically the only choice variable. There are some exceptions, however. For example, Lazear (1981) presents a model where worker productivity is variable. He examines how flexible hours contracts interact with workers' value marginal product (i.e., worker effort) on the job, and he recognizes that wage rates are able to allocate both hours of work and output per hour of a worker.? He does not address the issue of compensated wage changes - the main point at issue when evaluating the classical labor supply model. Pencavel (1977), however, does discuss (utility) compensated wage changes.

Pencavel examines a work effort model in which both effort and hours worked at a piece-rate job are inputs to a worker production function. The choice of work effort leads to ambiguously signed compensated wage effects on both work effort and hours worked. As we will see in the next section, I present a model that generates the same general prediction but with the following differences. First, in the Combined Model presented in Section II of this article, we derive results for income-compensated wage effects, whereas Pencavel's results are for utility-compensated wage effects. Also, Pencavel claims that the "strong substitution" of hours worked and work effort generates negative substitution effects. By "strong substitution" he means that an increase in hours worked will decrease effort. Our results show that substitution effects on hours of work are negative if the additional consumption of on-the-job leisure reduces the marginal utility of off-the-job leisure. This is not the same as saying that additional consumption of on-the-job leisure will reduce the consumption of off-the-job leisure. Furthermore, Pencavel seems to im-

${ }^{6}$ Robbins (1930) does look at work effort and argues in favor of a backwardbending labor supply curve in terms of effort and income.

${ }^{7}$ In his model, he shows that no flexible hours contract exists that increases utility of the workers (relative to a constrained hours contract) and increases firm profits. 
ply that if the substitution effect on either hours or effort is negative, then the other must be also. This is not the case in the Combined Model. These differences may seem trivial, but empirical results from this article support the Combined Model where they fail to support the model in Pencavel. For example, only half of our experimental subjects had substitution effects on work hours and effort of the same sign (for that subject). Moreover, of those whose effort decreased (increased) when hours worked increased (decreased), given a compensated wage change, only $25 \%$ displayed the anomalous negative substitution effect on hours of work. Both of these facts lend more support to the model extension in this article than to the model in Pencavel.

An exception to the predominantly theoretical literature on work effort is the growing body of empirical literature on work effort and piece-rate wage incentives. Oettinger (1998) examines the labor participation elasticity of baseball stadium vendors and finds that the participation elasticity is "positive and substantial." Lazear (1998) and Paarsch and Shearer (1998a and 1998b) use data sets in which employers switch from hourly or daily wage rates to piece rates. Lazear examines behavior at a large auto-glass installation company, while Paarsch and Shearer utilize data from a Canadian tree-planting firm. These studies, in addition to this article, all offer empirical support for the incentive effects of piece-rate wages. In addition, Lazear finds that piece rates attract a higher-ability work force and Paarsch and Shearer report that piece rates can also lead to fatigue (1998b) and lower quality of work (1998a).

Overall, the empirical literature has not carefully examined laborleisure choices that include both the hours of work choice and the work effort choice. Whether or not individuals behave according to any theory that includes both of these margins of interest remains an empirical question. Field studies are limited in their ability to provide the data required to answer this question. As such, controlled laboratory experimentation allows us to collect the data we need in a more controlled and cost-effective way in order to gain at least a preliminary understanding of behavior in this setting.

\section{The Combined Model of Hours Worked and Work Intensity}

The classical theory of labor supply assumes that time not spent at work is leisure time. It is clear that leisure can be consumed at work in multiple forms: coffee breaks, staring out the window on a sunny day, office gossip, etc. Let us then assume that utility is a function of consumption $(c)$, hours of work $(b)$, and productive hours at work $\left(b_{w}\right)$. Let the time constraint remain $b+l=T$, where $T$ is exogenous total time 
available. ${ }^{8}$ Also let $b=b_{w}+b_{l}$ where $b_{w}$ is time spent actually working and $b_{l}$ is hours of on-the-job leisure. Utility is now $U=\left(c, b_{w}, b_{l}\right)$, where $\partial U / \partial c>0, \partial U / \partial h_{l}>0, \partial U / \partial h_{w}<0$. The budget constraint is now $F+w h_{w}=p c$, implying that $w$ is a piece-rate wage (i.e., a wage per hour of productive work). Piece-rate (or quasi piece-rate) wages are actually quite commonplace in natural work environments and include contract work, fruit and vegetable picking, waiting tables and other work that pays tips (since tips are the majority of the workers' pay), and a wide variety of sales jobs that pay on commission.

This framework allows us to consider three different cases. First, we have the classical labor supply model when $h_{l}=0$ (i.e., $b_{w}=b$ ) and workers choose just $b$. The Slutsky equation is then $\partial b / \partial w=\left.(\partial b / \partial w)\right|_{m=\bar{m}}$ $+b(\partial h / \partial m)$, where $m=\bar{m}$ refers to the total income compensation. As usual, the Slutsky substitution effect will be positive, given well-behaved preferences, and the income effect will be positive (negative) for a normal (inferior) good.

Unfortunately, most laborers do not have the choice to vary the leisure they consume daily by merely leaving work earlier or later. Although this may be possible in the long run by choosing different jobs, it is not how we would usually describe short-run work behavior. Altonji and Paxson (1986) note that much of the variance in hours worked is associated with the jobs themselves and is therefore not at the discretion of the employee. In other words, firms many times have strong preferences for the hours worked by their employees. It is then the case that $b$ is fixed exogenously by the employer, and the choice variable is now $b_{w} .{ }^{9}$ This second case, which we will call the Intensity Model, yields as Slutsky equation

$$
\frac{\partial h_{w}}{\partial w}=\left.\frac{\partial h_{w}}{\partial w}\right|_{m=\bar{m}}+h_{w} \frac{\partial h_{w}}{\partial m} .
$$

Given that $\partial U / \partial h_{w}<0$, we would also predict positive substitution effects (and compensated wage elasticities) for work effort in the Intensity Model. A similar prediction is found in Pencavel (1977). Such a prediction has important implications for personnel management since it implies that

${ }^{8}$ Of course, it would be incorrect to say then that all time away from "work" is leisure. Household production is not considered in this article. The interested reader is directed to Becker (1965).

${ }^{9}$ This way of framing the labor-leisure choice for experimentation was suggested by Cameron Rookley. The idea of consuming leisure at work, however, has been around for a long time. Lewis (1957) notices that leisure is not homogenous, and casual observation that most individuals prefer "at home" leisure to "at work" leisure can be attributed, at least in part, to work facilities and their offerings of leisure choices. 
on-the-job work effort could be increased while holding total compensation (income) constant, at a base effort level, by implementing a compensated wage increase. We will directly test this prediction with one of the experimental designs presented in the following section. If it is true, though, that the Intensity Model applies to worker choice, and we estimated wage equations based on measures of hours of work, then calculated elasticities should be reevaluated. In such a scenario, an estimated substitution effect on $b$ is not measuring the response of workers to compensated wage changes (since in this model, there is no choice and therefore no changing of $b$ by the worker). Rather, it would be measuring employers' willingness to offer different work schedules for different wages at different jobs. This may be of interest as well, but it misses the point of how wage changes affect worker behavior-through changes in work effort.

For those jobs that allow hours of work choice, recall that the classical model does not allow individuals to enjoy on-the-job leisure. In reality, an employer cannot preclude employees from enjoying some on-the-job leisure even when they may choose how long they stay at work. Lewis (1957) notes that, while some argue that mixing business with pleasure spoils both, it apparently does not completely spoil both, given the existence of many forms of on-the-job leisure. ${ }^{10}$ Let us call the model where individuals choose both hours of work and productive hours at work (or hours of on- and off-the-job leisure) the Combined Model of labor supply. While the earlier derivation of the income-compensated Slutsky equation for the classical model was not presented due to the widespread use of the model (and, similarly, the derivation of the Intensity Model Slutsky equation is a straightforward extension of the classical model), the reader is directed to appendix A for a more complete and thorough derivation of the Slutsky equation for the Combined Model of labor supply. To facilitate the process, we cast the model in terms of "goods," and below we present the abbreviated results of this three-good maximization problem - the goods being consumption, off-the-job leisure, and on-the-job leisure.

For notational simplicity, let us call $c, l$, and $h_{l}$ goods 1,2 , and 3, respectively, and let $p=1$ be the numeraire. We can more fully take advantage of the implication of utility maximization when the problem is defined in terms of these three "goods." Notice, however, that an individual's choice of these three goods must necessarily determine a choice of $b$ and $h_{w}$ as well. First and second order derivatives will be denoted as numbered subscripts. For example, $U_{1}$ is the marginal utility of consump-

${ }^{10}$ Lewis (1957) discusses the possibility that travel costs (to leisure choices) may influence the leisure mix as well. 
tion, and $U_{23}=U_{32}$ is the change in the marginal utility of off-the-job leisure hours with respect to a change in on-the-job leisure time. Consequently, from the time constraint $T=b+l$, the sign of the incomecompensated substitution effect on leisure hours, $l$, will be the opposite of the sign of the substitution effect on work hours, $b$. Let us also assume quasi concavity of the utility function. The first-order conditions of the constrained three-good maximization problem combined with the implicit function theorem allow us to write the labor supply solutions to the maximization problem as

$$
b=b(w, F)
$$

and

$$
h_{w}=h_{w}(w, F) .
$$

Equations (2) and (3) result from the leisure choice solutions $l=l(w, F)$ and $h_{l}=h_{l}(w, F)$, and these functions are more complicated than before. ${ }^{11}$ We can write our newest Combined income-compensated Slutsky equation (on leisure hours) as

$$
\frac{\partial l}{\partial w}=\left.\left(\frac{\partial l}{\partial w}\right)\right|_{m=\bar{m}}+b_{w} \frac{\partial l}{\partial F} \frac{\lambda}{|J|}\left[w\left(U_{13}-U_{12}\right)+U_{23}-U_{33}\right]+b_{w} \frac{\partial l}{\partial F}
$$

where $\lambda$ is the Lagrange multiplier for the budget constraint, $|J|$ is the determinant of the Jacobian matrix defined by the system of equations in the first-order conditions of the maximization problem (which is guaranteed $<0$, given utility maximization), and again $U_{i j}$ represents the appropriate second-order derivative of the utility function with respect to variables $i$ and $j$ (where $U_{i j}=U_{j i}$ ).

The first term in brackets in equation (4) is the new combined Slutsky substitution effect on off-the-job leisure hours. ${ }^{12}$ The salient result is that, in the Combined Model, we cannot theoretically sign the substitution effect. While this is relevant, given the fact that there exist many different types of piece-rate wage labor, the result does not hold for an hourly wage scheme. ${ }^{13}$ In general, the income effect has no theoretical sign, as is

${ }^{11}$ The difference lies in the fact that one price (the wage) motivates decisions on two goods $\left(l\right.$ and $\left.b_{l}\right)$ in the Combined Model. The substantially more complex Slutsky equation results from extensive second-derivative interaction among the choice variables.

${ }^{12}$ A symmetric equation can be derived for the effect of a wage change on $h_{l}$.

${ }^{13}$ When one considers the classical model that is nested in the framework of this article, piece-rate wages are identical to hourly wages since effort is fixed. The 
true in the classical model (see the expanded term in app. A). If off-thejob leisure is a normal good, then the income effect on $l$ will be positive.

To see that the Combined Model can produce theoretically negative substitution effects on hours of work, it will suffice to show that we can have theoretically positive substitution effects on hours of leisure. From the complete derivation (app. A) we see that the full substitution effect terms for off-the-job leisure, $l$, and on-the-job leisure, $h_{l}$, can be arranged and written as

$$
\left.\left(\frac{\partial l}{\partial w}\right)\right|_{m=\bar{m}}=\left\{\left.\left(\frac{\partial l}{\partial w}\right)\right|_{m=\bar{m}} ^{*}+\frac{\lambda}{|J|}\left[w^{2} U_{11}+U_{32}-w\left(U_{31}+U_{12}\right)\right]\right\},
$$

where $\left.(\partial l / \partial w)\right|_{m=\bar{m}} ^{*}$ would be the usual (negatively signed) substitution effect on $l$, and

$$
\left.\left(\frac{\partial h_{l}}{\partial w}\right)\right|_{m=\bar{m}}=\left[\left.\left(\frac{\partial h_{l}}{\partial w}\right)\right|_{m=\bar{m}} ^{*}+\frac{\lambda}{|J|}\left(w^{2} U_{11}+U_{23}-w\left(U_{21}+U_{13}\right)\right)\right],
$$

where $\left(\partial h_{l} / \partial w\right)_{m=\bar{m}}^{*}$ would be the usual (negatively signed) substitution effect on $b_{l}$. Notice the symmetry in equations (5) and (6). It is obvious from the possible combinations of signs in the second portion of the substitution effect in equation (5) that this portion could be positive and, if stronger than the negative portion of the substitution effect, could create an overall positive substitution effect on $l$ (or on $h_{l}$ in eq. [6]). Such a positive substitution effect on $l$ would guarantee a negative substitution effect on $b$.

The next question to follow is: what are the assumptions necessary for a negative substitution effect on hours of work? To answer this, we exploit the fact that we could combine some terms (see app. A) and rewrite equation (5) as

results of the Combined Model, however, do not all hold for hourly wages. If this same model considers hourly wages, and workers choose $b$ and $b_{z w}$, then the compensated wage effect on hours of work is guaranteed to be positive, while the effect on work effort is ambiguous. Therefore, the interaction of $h$ and $b_{w}$ still leads to some ambiguity of results, but the ambiguity is in the compensated wage effect on work effort, not on hours of work. It is therefore important to be able to identify from field data whether wages are predominantly piece rate or hourly in terms of interpreting the results of the classical model. Even with hourly pay, however, the full effect of a wage change on the "work" decision is incomplete if on-the-job leisure is prevalent and ignored. 


$$
\left.\left(\frac{\partial l}{\partial w}\right)\right|_{m=\bar{m}}=\frac{\lambda}{|J|}\left[w\left(U_{13}-U_{21}\right)+U_{23}-U_{33}\right] .
$$

Equation (6) can be rewritten as

$$
\left.\left(\frac{\partial h_{l}}{\partial w}\right)\right|_{m=\bar{m}}=\frac{\lambda}{|J|}\left[w\left(U_{12}-U_{31}\right)+U_{32}-U_{22}\right] .
$$

Let us start by looking at a simplified case where we assume that there is no second-derivative interaction between either of the leisure goods and the consumption good (i.e., $U_{12}=U_{13}=0$ ). In this case the combined substitution effects in equations (7) and (8) will be positive if, respectively, $U_{23}<U_{33}$ and $U_{32}<U_{22} \cdot{ }^{14}$ Notice that this implies that $U_{23}\left(=U_{32}\right)$ is negative, which is sufficient under these assumptions to give a positive sign to the second portion of the combined substitution effects from equations (5) and (6). In terms of the compensated wage effect on hours of work, we can summarize the simplified case by saying that $U_{23}<0$ is a necessary condition for a negative substitution effect on hours of work, and $U_{23}<U_{33}$ is a sufficient condition. One example of a specific utility function that would generate such results would be $U\left(c, l, h_{l}\right)$ $=c+\left(b_{l} / l\right)+\ln (l)$. Here, all the assumptions of the simplified case are met as long as $l>2 b_{l}$ (again, reasonable considering what $l$ and $b_{l}$ refer to).

What does it mean for $U_{23}$ to be negative? It seems reasonable to assume that if on- and off-the-job leisure are substitutes then the additional consumption of one of these leisure goods would reduce the marginal utility of the other. So, we would then predict positive substitution effects on $l$ and $h_{l}$ if the decrease in marginal utility from consuming the "other" type of leisure is stronger than the own-good diminishing marginal utility (i.e., $U_{23}<U_{33}$ and $U_{32}<U_{22}$ ). Such a condition might

${ }^{14}$ These same restrictions would also guarantee that the income effects on these two types of leisure are negative (i.e., inferior leisure goods). To see this, notice that we can expand the income-effect equations to get

$$
\frac{\partial l}{\partial F}=\frac{-1}{|J|}\left[w U_{11}\left(U_{33}-U_{23}\right)+w\left(U_{13} U_{12}-U_{13}^{2}\right)+U_{31} U_{23}-U_{12} U_{33}\right]
$$

and

$$
\frac{\partial h_{l}}{\partial F}=\frac{1}{|J|}\left[w U_{11}\left(U_{32}-U_{22}\right)+w\left(U_{12}^{2}-U_{12} U_{31}\right)+U_{22} U_{31}-U_{12} U_{32}\right] .
$$

Under the simplified assumptions, these reduce to $\partial l / \partial F=(-1 / \mid J)\left[w U_{11}\left(U_{33}\right.\right.$ $\left.\left.-U_{23}\right)\right]$ and $\partial h_{l} / \partial F=\left(1 /|J|\left[w U_{11}\left(U_{32}-U_{22}\right)\right]\right.$. Therefore, if $U_{23}<U_{33}$ and $U_{32}<U_{22}$, then both leisure goods are inferior. 
be labeled "strong substitution." 15 With this strong substitution, consuming more of one type of leisure would strongly reduce the marginal utility that an individual would receive from consuming the other leisure good. The theoretical implication of this strong leisure substitution is a negative Slutsky substitution effect on hours of work, $h .{ }^{16}$ This is the Combined Model result that is at odds with the classical prediction under certain plausible assumptions and piece-rate wages.

Of course, it may be that $U_{12 \neq 0}$ and/or $U_{13 \neq 0}$. In this case, we might intuitively assume that $U_{12}$ and $U_{13}$ are positive. Why? Recall that good 1 is the consumption good, and if $U_{12}$ and $U_{13}$ are positive, then the marginal utility of each type of leisure is increased by consuming more $c$. It seems logical to conclude that either type of leisure and consumption, which can be enjoyed at the same time, are complements, while on- and off-the-job leisure, which cannot be consumed together, are substitutes. If we still assume that $U_{23}<U_{33}$, then a positive combined substitution effect on $l$ results if $U_{21}>U_{31}$ in equation (7). ${ }^{17}$ In other words, we have a positive substitution effect on $l$ if off-the-job leisure is "more complementary" with consumption than is on-the-job leisure. From equation (7) we see that this is a sufficient, but not necessary, condition for a positive Combined Model substitution effect on $l$ (i.e., a negative substitution effect on $b$ ).

We conclude then that a negative compensated wage effect on hours of work in our new Combined Slutsky equation (resulting from a positive effect on hours of leisure) would result if off-the-job leisure is considered more complementary to consumption than is on-the-job leisure, and if on- and off-the-job leisure are "strong" substitutes. The sufficient condition is that $U_{21}>U_{13}$ and $U_{23}<U_{33}$. This is a very intuitive result, considering that the set of on-the-job leisure choices is often much more restricted than the set of off-the-job leisure choices. Under the more restrictive assumptions that $U_{12}=U_{13}=0$, then the strong substitution of $l$ and $h_{l}$ are sufficient for a negative compensated wage effect on $b$. Complementarity of these two leisure goods seems less intuitive. It only makes sense if we can imagine how an increase in one type of leisure could actually increase the marginal utility of consuming the other. This might be the case if one type of leisure good is a prerequisite to consuming the

${ }^{15} \mathrm{Keep}$ in mind that this is different from the strong substitution discussed earlier in Pencavel (1977).

${ }^{16}$ This does not, however, guarantee that the compensated wage effect for on-the-job leisure is of a particular sign given that we do not assume that $U_{22}$ $=U_{33}$. Therefore, the sign of the compensated wage effect on productive work hours, $h_{w}$, cannot be determined without making further assumptions.

${ }_{17}$ With these additional assumptions, income effects now have an indeterminate sign, as is the case in the classical model. 
other (e.g., taking time off at work to make dinner reservations and, therefore, to avoid a wait at the restaurant).

\section{Experimental Designs}

The two experimental designs used to test the implications of the Intensity and Combined Models are called, respectively, the Intensity Experiment and the Combined Experiment. ${ }^{18}$ The Intensity Experiment mimics many short-run work environments in which workers do not choose their hours of work. In this environment we examine whether or not there is any predictable wage effect on $b_{w}$. More specifically, a wage change is decomposed across multiple experimental work days in order to observe if substitution effects on work effort are positive as predicted. In the Combined Experiment, we also decompose wage changes to observe substitution effects. Here, negative substitution effects on $b$ would favor the Combined Model of labor supply over the classical labor supply model that predicts only positive substitution effects on $b$. In both designs, some subjects receive a wage increase and others receive a wage decrease so that we can test whether or not increases and decreases are responded to differently. First, we discuss several features that are common to both experiments.

Subjects are recruited for a 2-hour experiment each day for 4 days. The first day of experimentation is to train the subjects in the work environment, and so only (the final) 3 days are discussed henceforth. Subjects were all undergraduate students at the University of Arizona. The experimental days are not consecutive primarily due to the recruiting difficulties that arise with students who are scheduled for classes on 2 or 3 days of the week, but all experimental days were completed for any given subject within a 9-day period. ${ }^{19}$ During each experiment, subjects perform a rather dull task in exchange for payment. ${ }^{20}$ The task consists of typing the same paragraph repeatedly for a fixed wage each time successfully typed and printed. Typing is a task that each individual is reasonably capable of performing. To control for learning of a specific paragraph across days, subjects type a different paragraph of the same difficulty level

\footnotetext{
${ }^{18}$ Copies of all experimental instructions are available from the author on request.

${ }_{19}$ More specifically, subjects completed the 4-day experiment either during a Monday-Wednesday-Friday-Monday sequence of days or a Tuesday-ThursdayTuesday-Thursday sequence.

${ }^{20} \mathrm{~A}$ task that is enjoyable to the subjects would blur the line between labor and leisure and make interpretation of the results much more difficult. Subject comments on finishing the experiment assured me that $I$ had succeeded in finding a "no-leisure" task for them to perform.
} 
each day of the experiment, and the order of the paragraphs is randomized across days. ${ }^{21}$

Paying the subjects for each paragraph typed represents a piece-rate wage schedule. A piece-rate wage allows work intensities to be successfully observed while limiting experimenter interaction. If an hourly wage were used, the experimenter must then be concerned with monitoring and shirking. Let us subsequently refer to this piece-rate waged merely as the "wage," denoted $w$. There is also a fixed payment $F$ that serves as nonlabor income for the experiment. The amount of $F$ is exogenous for the subject at the start of the experiment. After the first work day, wages are increased for some subjects and decreased for others in order to see if subjects responded differently to wage increases and decreases. When performing this income-compensated wage change on a subsequent work day, $F$ is varied by an amount that depends on total paragraphs typed on the first day.

In order to avoid subjects merely typing as fast as they can to earn money but ignoring the quality of their work, a simple quality control scheme is used. Subjects that print a paragraph of output in which more than five mistakes are found by the experimenter are not paid for that unit. A mistake is any deviation from the exact paragraph to be copied that is spotted by the experimenter (e.g., spelling, punctuation, spacing). This is all carefully explained to the subjects in the instructions. ${ }^{22}$

The first combination of $w$ and $F$, called $w_{a}$ and $F_{a}$, is the baseline treatment A. For all subjects in both experimental designs, $w_{a}=\$ .15$ and $F_{a}=\$ 13.00$ for those subjects that would subsequently receive a wage increase and $w_{a}=\$ .45$ and $F_{a}=\$ 5.00$ for those that would receive a wage decrease. Pilot experiments helped to determine these as suitable levels of $w$ and $F$ for motivating the subjects. ${ }^{23}$ Subjects then receive either a wage increase or a wage decrease with approximately half receiv-

${ }^{21}$ Pilot experiments revealed that subjects remember substantial portions of the paragraph on the following day when the same paragraph was used on all 4 days. Choosing paragraphs of the same difficulty level controls for this type of learning. Any possible learning within an experimental work day is not controlled for in this design.

${ }^{22}$ In only one of all the experimental days did a subject not get credit for a paragraph. This happened on the first day of the experiment, which is merely a training day, and does not alter the data analysis in this article.

${ }^{23}$ While the first day of experimentation is not used in the data analysis or reported in this article, subjects were paid $w=\$ .30$ and $F=\$ 4.00$ for that day, and the data are available on request. In general, the wage must be high enough to offset any possible source of outside income that the subjects may choose to earn by leaving the experiment as soon as possible. A high enough wage also ensures that the motivating factor for staying and working is earning income, and the motivating factor for leaving is that the subject has chosen his or her optimal amount of labor supplied. 
Table 1

Experimental Design

\begin{tabular}{|c|c|c|c|}
\hline & Day A* & Day B* & Day C \\
\hline $\begin{array}{l}\text { Wage increase } \\
\text { Subjects } \\
\text { Wage decrease } \\
\text { Subjects }\end{array}$ & $\begin{aligned} w_{a} & =.15 \\
F_{a} & =13.00 \\
w_{a} & =.45 \\
F_{a} & =5.00\end{aligned}$ & $\begin{aligned} w_{b} & =.45 \\
F_{b} & <13.00 \dagger \\
w_{b} & =.15 \\
F_{b} & >5.00 \dagger\end{aligned}$ & $\begin{aligned} w_{c} & =.45 \\
F_{c} & =13.00 \\
w_{c} & =.15 \\
F_{c} & =5.00\end{aligned}$ \\
\hline
\end{tabular}

\footnotetext{
* Recall that these are actually days 2,3 , and 4 of the experiment. The first day of the experiment was training. Days $B$ and $C$ were randomized in order so that some subjects faced an $A B C$ design, while others faced an $A C B$ design.

$\dagger$ The exact amount of nonwage income on these days depends on the number of paragraphs typed on day A. The Slutsky compensations are such that if the subject would have typed the same number of paragraphs on day $B$ as on day $A$, the subject would have earned the same amount of wage plus nonwage income.
}

ing a wage decrease and half receiving a wage increase. The final two days of the experiment allow for the decomposition of the wage change. Day $B$ consists of an income-compensated wage change. Wages and nonwage income are changed to $w_{b}$ and $F_{b}$, where $F_{b}$ is the new level of $F$ needed to make the original (total income) choice point from day $A$ attainable if the subject types the same number of paragraphs as on day $A$. Day $C$ then returns nonwage income back to its original (day A) level while paying wages $w_{c}=w_{b}$. The comparison of outcomes on days $\mathrm{A}$ and $\mathrm{C}$ gives us an income effect, while comparing days $\mathrm{A}$ and $\mathrm{B}$ gives us a substitution effect. On day A, subjects did not know what future wages or nonwage income would be, not even whether they would rise or fall. The 3-day experimental design is summarized by table 1 .

Payment information is private information for each individual. Any possible wealth effects, if they exist in laboratory settings, are not controlled for in this design. ${ }^{24}$

In the Intensity Experiment, subjects are required to stay and work for the full 2-hour experimental day. The only choice being made in the Intensity Experiment, therefore, is $h_{w}$. In the Combined Experiment, subjects are free to perform their "job" for as long as they would like up to a 2-hour limit. ${ }^{25}$ Once a subject does not care to work

${ }^{24}$ For a discussion of methods of controlling for wealth effects, see Davis and Holt (1993). Most of the concern over wealth effects has been in the context of lottery choices. Cox and Epstein (1989) do not find much evidence for wealth effects on lottery-choice experiments, but others (Ang and Schwarz 1985) have not ruled out wealth effects, although other possible explanations accompany wealth-effect explanations of risk premiums. More effort needs to be expended to document the existence of wealth effects.

${ }^{25}$ Given this rule, rationed labor supply is a potential issue. If individuals would otherwise choose $b$ greater than 2 hours-meaning the constraint is binding - then the substitution effects are nonexistent for wage increases. Ashen- 
anymore, he collects an IOU for that experimental day's earnings, and then he leaves. In the Combined Experiment, subjects are therefore choosing both $h$ and $h_{w}$.

Subjects are required to complete a minimum number of paragraphs in the Combined Experiment. We do this for two reasons. First, it helps eliminate possible feelings of obligation to work in order to cooperate with the experimenter, even though the subjects would rather leave. Second, it can be thought of as simulating a minimum amount of labor to be supplied in order to survive and continue on to the next day. The minimum amount is otherwise arbitrary and is three paragraphs. ${ }^{26}$

Since each subject serves as his own baseline, differences in preferences pose no problem in the comparative static analysis. It is irrelevant that we cannot distinguish between a slow typer and a fast typer who takes breaks since what is important is how each subject reacts to his own compensated piece-rate wage change. In fact, preference heterogeneity is expected in the laboratory just as in the naturally occurring economy. The simple foundation on which these experiment designs work is that subjects bring their own homegrown preferences into the lab to perform labor tasks, facing payment packages ( $w$ and $F$ ) with differing marginal and average payoffs. ${ }^{27}$

\section{Experimental Results}

All experimental subjects were undergraduates at the University of Arizona who were recruited from economics courses. Total experimental costs (including pilot experiments) were $\$ 3,084$. Payoffs for the 15 subjects in the Intensity Experiment ranged from $\$ 5.32$ to $\$ 11.58$ an hour for the 2-hour session (plus a $\$ 5.00$ show up fee on the first day) with an average hourly payoff of $\$ 8.22$. Hourly payoffs for the 26 subjects in the

felter (1980) discusses this in the context of aggregate labor supply. Ham (1982) also notes that this would cause least squares estimates of a variable's effect on $b$ to be misstated. However, it is difficult to know whether or not subjects are truly constrained when choosing the maximum level of $b$. Furthermore, in only about $5 \%$ of the experimental work days of this article did subjects choose the upper limit of 2 hours, and it seems to be of limited importance for interpretation of the results of these experiments.

${ }^{26}$ Border solutions occurred for only a minority of the subjects. Out of a possible 78 days ( 26 subjects for 3 days each), on only 14 days did subjects work the minimum amount, and on only 4 days did they work the maximum.

${ }^{27}$ It is true that some degree of control is lost by allowing subjects to choose when they leave the experiment, but such a labor supply experiment cannot be made interesting with induced-valued theory (which would induce value upon leisure choices by paying subjects to enjoy leisure). The trade-off is worthwhile when one considers that real preferences are being examined. 
Combined Experiment ranged from $\$ 8.10$ to $\$ 36.24$ (plus a $\$ 5.00$ show up fee on the first day) with an average hourly payoff of $\$ 16.28 .^{28}$

\section{The Intensity Experiment}

We will first discuss the Intensity Experiment since its environment allows for only one leisure choice: the on-the-job leisure choice. The Intensity Experiment was run on 15 subjects. ${ }^{29}$ Recall that in the Intensity Experiment, subjects must work the full 2-hour session each day, and therefore they choose $b_{w}$. The best proxy for $b_{w}$ on a given day is the average paragraph production time that moves in the opposite direction of $b_{w}$. In other words, a subject who works harder on different experimental days will exhibit a lower average paragraph production time on the day in which he or she chooses a higher $b_{w}{ }^{30}$ Wages, nonwage income, average paragraph production times, and the signs of the wage effects are reported in table 2.

From table 2 we see that the substitution effect has the predicted positive sign in 11 of 15 cases - when given a compensated wage increase (decrease), subjects worked harder (less hard). In other words, when subjects cannot choose $h$, the Intensity Model appears to describe behavior rather well. This can be viewed as a very conservative test of the theory since subjects had no on-the-job leisure possibilities other than working less hard (i.e., no talking among colleagues, coffee breaks, etc.). A negative income effect here implies that on-the-job leisure is a normal good for nine of 15 subjects, while total wage effects show that nine of 15 subjects displayed an upward sloping $h_{w}$ supply curve.

Given the size of the data set from the Intensity Experiment (45 data points -15 subjects for 3 days each), we are not claiming to be able to estimate population parameters, and we are clearly limited in terms of

${ }^{28}$ The overall higher hourly payment in the Combined Experiment results from the subjects having the option of leaving relatively early in the day and keeping their entire fixed payment. Per person total compensation was actually higher in the Intensity Experiment.

${ }^{29}$ It should be noted that on the third experimental day for subjects 1-4 the printer being used became inoperable during the last 10 minutes of the experiment. Subjects were still able to type, and the resulting paragraph times were replaced with that subject's mean production time for that day. This is an unbiased estimate of the production times of the subjects since subjects are assumed by theory to choose $h_{w}$ for the day and not for each individual paragraph. The whole problem involved replacing production times for no more than three paragraphs for any of these subjects.

${ }^{30}$ Since $b$ is fixed in the Intensity Experiment, one could also use the total number of paragraphs typed in a day as a proxy for $b_{w}$. Such a proxy would not work, however, in the Combined Experiment since the average paragraph production time would then be confounded by the choice of $h$. 
Table 2

Intensity Experiment: Wages, $F$, Average Production Times (in Minutes), and Signs of Wage Effects on $b_{w}$

\begin{tabular}{|c|c|c|c|c|c|c|c|c|c|}
\hline \multirow{2}{*}{$\begin{array}{l}\text { Subject } \\
\text { Number }\end{array}$} & \multicolumn{2}{|c|}{ Day A } & \multicolumn{2}{|c|}{ Day B } & \multicolumn{2}{|c|}{ Day C } & \multicolumn{3}{|c|}{ Sign of Wage Effect on $b_{w}$} \\
\hline & $F(\$)$ & Time & $F(\$)$ & Time & $F(\$)$ & Time & Substitution & Income & Total \\
\hline $1 *$ & 5.00 & 6.13 & 10.70 & 6.12 & 5.00 & 6.08 & $-\dagger$ & - & - \\
\hline 2 & 5.00 & 3.16 & 16.40 & 6.68 & 5.00 & 2.81 & + & - & - \\
\hline 3 & 5.00 & 5.55 & 11.00 & 5.83 & 5.00 & 5.47 & + & - & - \\
\hline 4 & 5.00 & 4.42 & 12.80 & 7.17 & 5.00 & 7.96 & + & + & + \\
\hline 5 & 5.00 & 4.71 & 12.50 & 4.91 & 5.00 & 5.90 & + & + & + \\
\hline 6 & 5.00 & 3.87 & 14.00 & 3.43 & 5.00 & 3.37 & $-\dagger$ & - & - \\
\hline 7 & 5.00 & 5.86 & 11.00 & 6.54 & 5.00 & 7.03 & + & + & + \\
\hline 8 & 5.00 & 6.85 & 10.10 & 6.80 & 5.00 & 7.44 & $-\dagger$ & + & + \\
\hline 9 & 13.00 & 3.58 & 3.10 & 3.39 & 13.00 & 3.65 & + & - & - \\
\hline 10 & 13.00 & 5.83 & 7.00 & 4.68 & 13.00 & 4.78 & + & - & + \\
\hline 11 & 13.00 & 5.09 & 6.10 & 5.02 & 13.00 & 5.04 & + & - & + \\
\hline 12 & 13.00 & 3.44 & 2.80 & 2.88 & 13.00 & 3.11 & + & - & + \\
\hline 13 & 13.00 & 3.59 & 3.40 & 4.55 & 13.00 & 3.82 & $-\dagger$ & + & - \\
\hline 14 & 13.00 & 5.22 & 6.10 & 4.73 & 13.00 & 4.81 & + & - & + \\
\hline 15 & 13.00 & 4.64 & 2.20 & 4.25 & 13.00 & 4.06 & + & + & + \\
\hline
\end{tabular}

NOTE. - The substitution effect sign is found by comparing columns 5 and 3 (keeping in mind the sign of the wage change), the income effects by comparing columns 7 and 5 , and the total effect by comparing columns 7 and 3. Given piece-rate wages, income compensations on day B are such that if the subject typed the same number of paragraphs on day $B$ as on day A, total compensation would be held constant. As a result, it is possible that different individuals are compensated the same amount even though slight variations in average paragraph production time may exist.

* Subjects 1-8 faced a wage decrease $\left(w_{a}=\$ .45, w_{b}=w_{c}=\$ .15\right)$. Subjects $9-15$ faced a wage increase $\left(w_{a}=\$ .15, w_{b}=w_{c}=\$ .45\right)$.

$\dagger$ Represents a violation of the prediction of the Intensity Model.

what statistical analyses we can do. Nevertheless, a simple regression will allow us to calculate an average $b_{w}$ function such as

$$
\text { AvrTime }=\alpha+\beta_{1} w a g e+\beta_{2} F+\varepsilon .
$$

This ordinary least squares (OLS) model is rejected in favor of a fixedeffects modeling, and so the estimated version of equation (9) includes individual specific constant terms. The estimated equation is

$$
\begin{aligned}
\text { AvrTime }= & \overline{5} . \overline{2} \overline{1}-1.51 \text { wage }+.02 F \\
& (.00)(.11)
\end{aligned}
$$

Here, $p$-values are given in parentheses, and the constant term is the mean level of fixed effect (and mean $p$-value). The adjusted $R^{2}=.67$ and $N$ $=45 .^{31}$

${ }^{31}$ A Lagrange Multiplier test favors a one-factor model over the classical linear regression with no group specific effects $(p=.00)$, and the Hausman test suggests the fixed-effects model over the random-effects model $(p=.07)$. The 
The income-compensated wage (substitution) effect on AvrTime from $\left(9^{\prime}\right)$ is $\beta_{1}-($ AvrTime $) \beta_{2}=-1.61$ calculated at the mean value of AvrTime (4.98 minutes), while the compensated wage elasticity is -.10 . Therefore, the $\$ .30$ compensated increase (decrease) in the wage decreases (increases) the average paragraph production time by about 29 seconds (about 10\%, given the mean time of 4.98 minutes). The negative substitution effect implies a positive substitution effect on $b_{w}$. This result is consistent with the predictions of the Intensity Model from equation (1). The income effect is positive, implying that on-the-job leisure is a normal good, but it is small in magnitude and insignificant (the total income elasticity $=.01$ ). The uncompensated wage effect of -1.51 is marginally insignificant and implies an average positively sloped $b_{w}$ supply curve. Specifically, an increase (decrease) in the wage of $\$ .30$ caused AvrTime to decrease (increase) by 27 seconds (the total wage elasticity of average production time $=-.09) .{ }^{32}$ These results are consistent with those of the fixed-hours environments studied in Lazear (1998) and Paarsch and Shearer (1998a) in that, when total compensation is more tied to effort, effort or productivity rises. ${ }^{33}$ What is of empirical interest from the Intensity Experiment is that wage changes still affect labor choices in environments in which workers cannot choose hours of work - on-thejob leisure (or less of it) is chosen instead.

We might also be interested in the results of estimating equation (9) when the day $B$ data are omitted. While theoretically exogenous, nonwage income $F$ is not exogenous in the experimental design for day $\mathrm{B}$, since it depends upon the amount of work performed in day A. As a result, the

fixed-effect estimation results did not, however, substantially alter the coefficient estimates over the OLS estimation of eq.(9). While it is a rejected specification, the OLS model will serve as a comparison to the estimated OLS model of the Combined Experiment data. The estimated OLS equation (with robust variance estimates allowing for nonindependence among observations of the same crosssectional unit) for the Intensity Experiment is AvrTime $=6.52-3.55 \mathrm{wage}$ - .06F. The $p$-values were $.00, .01$, and .32 , respectively for $\alpha, \beta_{1}$, and $\beta_{2}$. The estimated OLS $\beta_{1}$ does, however, increase the magnitude of the compensated wage elasticity to -.20 compared to the elasticity of -.10 for the fixed-effects specification.

${ }^{32}$ The OLS model in eq. (9) was also estimated with an additional interaction term wage $F$ (equal to wage $* F$ ) to see if the average level of compensation was significant. The coefficient on this variable (.16) was highly insignificant $(p$ $=.62)$, and the effect of the wage became larger in magnitude $(-4.98)$ and marginally insignificant ( $p=.12$ ). The effect of the variable $F$ was still small in magnitude $(-.11)$ and insignificant $(p=.35)$.

${ }^{33}$ Specifically, Lazear reports an increase in worker productivity of at least $22 \%$ when changing to a piece-rate pay system (from an hourly wage system). Paarsch and Shearer (1998a) find that productivity of tree-planters is about $23 \%$ higher under piece rates than under a fixed daily wage. 
coefficient estimates will be biased if there is any correlation in the errors across experimental work days for an individual. When omitting the day B data, equation (9) is estimated by OLS to be: AvrTime $=6.60$ -1.70 wage $-.14 F$. The $p$-values for $\alpha, \beta_{1}$, and $\beta_{2}$ are, respectively, .00, .28 , and .03 . The real difference here is that most of the significance is now in nonwage income $F$ (estimated to be an inferior good). The wage effect, while statistically insignificant, still supports the implication of the Intensity Model from equation (1). ${ }^{34}$

\section{The Combined Experiment}

The Combined Experiment allows subjects to choose $h$ as well as $h_{w}$ by allowing subjects to leave whenever they choose during an experimental session. This experimental design was run on 26 subjects. The results are summarized in tables 3 and 4 . Wages, nonwage income, average paragraph production times, and total minutes worked are shown in table 3. From table 3 we can calculate the signs of the substitution, income, and total wage effects on $b$ as well as the sign of the compensated wage effect on $b_{w}$. These effects are then shown in table 4 .

From table 4 we can see that off-the-job leisure is a normal good for 14 of 26 subjects, and labor supply curves are upward sloping in 19 of 26 cases. We also see that the classical static labor supply theory is violated (i.e., there are negative substitution effects on $b$ ) in eight of 26 cases. ${ }^{35}$ The fact that eight of 26 subjects displayed negative substitution effects on $b$ suggests that on- and off-the-job leisure are strong substitutes for some individuals. It is even possible that all 26 subjects substitute on- and off-the-job leisure, but that the two types of leisure are only weak substitutes for those subjects who display a positive substitution effect on $b$. This is evidence in support of the Combined Model of labor supply.

${ }^{34}$ This is not estimated with a fixed-effects modeling since the regressors are colinear. Specifically, there is no variation in the individual-specific constant terms nor in $F$ once day B data are omitted.

${ }^{35}$ One may think that individual occurrences of negative hours of work responses (consistent with a downward sloping labor supply function) may be attributed to income targeting. The typical explanation of loss aversion or a point of nondifferentiability in the utility function at an income target would require subjects to treat off-the-job leisure as a normal good in order to smooth income. In fact, in all but one subject (subject 18) who displayed a downward sloping hours supplied function, off-the-job leisure is a normal good. However, with two different leisure choices available, the strong substitution off on- and off-the-job leisure (with $l$ being an inferior good) could also produce downward sloping hours supplied functions. The experimental data offer some support of this theory. Most instances of negative labor supply response (five of seven) are due to a negative substitution effect on $b$ that is theoretically consistent with the strong substitution of $l$ and $b_{l}$. 
Table 3

Combined Experiment: Wages, $F$, Average Production Times, and Total Work Time (in Minutes)

\begin{tabular}{|c|c|c|c|c|c|c|c|c|}
\hline \multirow[b]{2}{*}{$\begin{array}{l}\text { Subject } \\
\text { Number }\end{array}$} & \multicolumn{2}{|c|}{ Day A* } & \multicolumn{4}{|c|}{ Day B† } & \multicolumn{2}{|c|}{ Day $C \ddagger$} \\
\hline & $\begin{array}{c}\text { Average } \\
\text { Time }\end{array}$ & $\begin{array}{l}\text { Total } \\
\text { Time }\end{array}$ & Wage (\$) & $F(\$)$ & $\begin{array}{l}\text { Average } \\
\text { Time }\end{array}$ & $\begin{array}{l}\text { Total } \\
\text { Time }\end{array}$ & $\begin{array}{c}\text { Average } \\
\text { Time }\end{array}$ & $\begin{array}{l}\text { Total } \\
\text { Time }\end{array}$ \\
\hline 1 & 3.57 & 99.96 & .15 & 13.40 & 3.31 & 23.17 & 3.22 & 16.10 \\
\hline 2 & 8.35 & 41.75 & .15 & 6.50 & 7.93 & 23.79 & 7.69 & 23.07 \\
\hline 3 & 4.45 & 22.25 & .15 & 6.50 & 4.11 & 41.10 & 4.25 & 63.75 \\
\hline 4 & 4.03 & 76.57 & .15 & 10.70 & 3.09 & 61.80 & 3.41 & 68.20 \\
\hline 5 & 3.66 & 87.84 & .15 & 12.20 & 3.30 & 105.60 & 3.09 & 12.36 \\
\hline 6 & 3.07 & 101.31 & .15 & 14.90 & 2.76 & 8.28 & 3.28 & 13.12 \\
\hline 7 & 5.22 & 52.20 & .15 & 8.00 & 4.73 & 28.38 & 5.42 & 21.68 \\
\hline 8 & 6.69 & 80.28 & .15 & 8.60 & 6.33 & 25.32 & 7.55 & 30.20 \\
\hline 9 & 4.41 & 110.25 & .15 & 12.50 & 4.09 & 28.63 & 3.69 & 36.90 \\
\hline 10 & 5.58 & 106.20 & .15 & 10.70 & 5.65 & 28.25 & 6.18 & 24.72 \\
\hline 11 & 3.51 & 91.26 & .15 & 12.80 & 3.44 & 120.4 & 3.55 & 120.7 \\
\hline 12 & 5.20 & 62.40 & .15 & 8.60 & 4.61 & 23.05 & 5.24 & 20.96 \\
\hline 13 & 7.54 & 22.62 & .15 & 5.90 & 7.31 & 21.93 & 6.99 & 20.97 \\
\hline 14 & 4.77 & 114.48 & .45 & 5.80 & 4.91 & 49.10 & 5.07 & 40.56 \\
\hline 15 & 10.78 & 32.34 & .45 & 12.10 & 12.04 & 96.32 & 11.62 & 69.72 \\
\hline 16 & 8.32 & 41.60 & .45 & 11.50 & 7.22 & 72.20 & 7.26 & 65.34 \\
\hline 17 & 4.43 & 57.59 & .45 & 9.10 & 4.55 & 72.80 & 4.62 & 83.16 \\
\hline 18 & 4.80 & 67.20 & .45 & 8.80 & 5.75 & 23.00 & 5.12 & 51.20 \\
\hline 19 & 4.13 & 78.47 & .45 & 7.30 & 3.79 & 102.33 & 3.92 & 70.56 \\
\hline 20 & 5.09 & 30.54 & .45 & 11.20 & 4.02 & 44.22 & 3.95 & 90.85 \\
\hline 21 & 6.14 & 30.70 & .45 & 11.50 & 6.39 & 19.17 & 5.99 & 17.97 \\
\hline 22 & 5.76 & 28.80 & .45 & 11.50 & 6.12 & 55.08 & 5.94 & 23.76 \\
\hline 23 & 3.81 & 19.05 & .45 & 11.20 & 3.58 & 121.72 & 3.62 & 21.72 \\
\hline 24 & 6.55 & 19.65 & .45 & 12.10 & 3.97 & 11.92 & 4.39 & 43.90 \\
\hline 25 & 7.12 & 21.36 & .45 & 12.10 & 5.92 & 100.64 & 5.73 & 103.14 \\
\hline 26 & 11.57 & 34.71 & .45 & 12.40 & 10.24 & 30.72 & 8.88 & 124.32 \\
\hline
\end{tabular}

"For subjects $1-13$, wage $=\$ .45, F=\$ 5.00$. For subjects $14-26$, wage $=\$ .15, F=\$ 13.00$.

† Compensation is the same in the Intensity Experiment. Occasionally the total time typed exceeds 120 minutes (the 2-hour limit) because subjects were allowed to finish the paragraph that they were typing when reaching the time limit.

$\ddagger$ For subjects $1-13$, wage $=\$ .15, F=\$ 5.00$. For subjects $14-26$, wage $=\$ .45, F=\$ 13.00$.

Additional evidence is found in the last column of table 4. Here, we see that 17 of $26(65 \%)$ subjects display negative substitution effects on $b_{w}$. We can contrast this to only four of $15(27 \%)$ subjects displaying negative substitution effects on $b_{w}$ in the Intensity Experiment. These negative substitution effects on work effort (not just on hours of work) are also consistent with the Combined Model (see Sec. II). Yet such a prediction is at odds with the Intensity Model-a model supported by data from the Intensity Experiment. Empirically, we can see that when workers choose their hours of work, workers respond to wage changes by altering both hours of work and work effort.

A simple regression of $b$ on a constant, the wage, and nonwage income can aid us in determining whether or not the predictions of the classical 
Table 4

Combined Experiment ${ }^{*}$

\begin{tabular}{|c|c|c|c|c|}
\hline \multirow[b]{2}{*}{$\begin{array}{l}\text { Subject } \\
\text { Number }\end{array}$} & \multicolumn{3}{|c|}{ Effects on Hours of Work } & \multirow[b]{2}{*}{$\begin{array}{c}\text { Compensated Wage } \\
\text { Effect on } h_{w}\end{array}$} \\
\hline & $\begin{array}{c}\text { Substitution } \\
\text { Effect }\end{array}$ & $\begin{array}{c}\text { Income } \\
\text { Effect }\end{array}$ & $\begin{array}{c}\text { Total Wage } \\
\text { Effect }\end{array}$ & \\
\hline 1 & + & + & + & - \\
\hline 2 & + & - & + & - \\
\hline 3 & $-\dagger$ & - & - & - \\
\hline 4 & + & - & + & + \\
\hline 5 & $-\dagger$ & + & + & - \\
\hline 6 & + & - & + & - \\
\hline 7 & + & + & + & - \\
\hline 8 & + & - & + & - \\
\hline 9 & + & - & + & - \\
\hline 10 & + & + & + & + \\
\hline 11 & $-\dagger$ & - & - & - \\
\hline 12 & + & + & + & - \\
\hline 13 & + & + & + & - \\
\hline 14 & $-\dagger$ & - & - & - \\
\hline 15 & + & - & + & - \\
\hline 16 & + & - & + & + \\
\hline 17 & + & + & + & - \\
\hline 18 & $-\dagger$ & + & - & - \\
\hline 19 & + & - & - & + \\
\hline 20 & + & + & + & + \\
\hline 21 & $-\dagger$ & - & - & - \\
\hline 22 & + & - & - & - \\
\hline 23 & + & - & + & + \\
\hline 24 & $-\dagger$ & + & + & + \\
\hline 25 & + & + & + & + \\
\hline 26 & $-t$ & + & + & + \\
\hline
\end{tabular}

* Signs of wage and income effects on $b$. Sign of compensated wage effect on $b_{w}$.

$\dagger$ Represents a violation of the prediction of the classical static labor leisure choice model. The substitution, income, and total wage effect signs are found by comparing the appropriate total time columns from table 3 . The compensated wage effect on $h_{w}$ is found by comparing average time from days $\mathrm{A}$ and $\mathrm{B}$. Again, keep in mind the direction of the wage change when making the comparisons.

model are consistent with the findings of the Combined Experiment. The equation of estimation is

$$
b=\alpha+\beta_{1} w a g e+\beta_{2} F+\varepsilon .
$$

The data do not support a fixed-effects modeling of equation (10). Therefore, equation $\left(10^{\prime}\right)$ is the result of the OLS estimation of equation (13) with $p$-values in parentheses. ${ }^{36}$ Variance estimates implicit in equation

${ }^{36}$ The possibility of fixed or random effects was explored. For the specification in eq. (10) we find no support for fixed or random effects. As with the estimation of eq. (9) for the Intensity Experiment, eq. (10) was estimated with an additional interaction term wage $* F$. As with the Intensity Experiment data, this variable does not have a significant effect on $b$, and its inclusion into the specification 
$\left(10^{\prime}\right)$ are robust, allowing for the possible nonindependence of observations within a cross-sectional unit. The $R^{2}=.14$ and $N=78$.

$$
b=\underset{(.04)}{28.03}+83.00 \text { wage }+.03 F
$$

We see that at the aggregate level, the only significant variable in determining total time spent working is the wage. The constant is significant and, in part, reflects the minimum number of paragraphs that each subject had to type. The hours supplied function is upward sloping and implies that an increase (decrease) in the wage of $\$ .30$ will increase (decrease) minutes worked by about 25 minutes. ${ }^{37}$ Off-the-job leisure is an inferior good on average, although the effect of $F$ is statistically insignificant and very small in magnitude.

The income-compensated wage (substitution) effect on $b$ is $\beta_{1}-b \beta_{2}$ $=81.40$, calculated at the mean value of $b$ (53.19 minutes). A compensated increase in the wage of $\$ .30$ would then increase total time worked by 24 minutes. The elasticities calculated from equation $\left(10^{\prime}\right)$, evaluated at the mean values of $b$ and $w$ are an income-compensated wage elasticity of .46 , a total income elasticity of .01 , and an uncompensated wage elasticity of total minutes worked of .47. The estimated income-compensated wage elasticity of .46 is high but not without company in the empirical literature (see Pencavel [1986] for examples). ${ }^{38}$ A summary of the elasticity results from both experiments is in table $5 .{ }^{39}$

The estimation results in equation $\left(10^{\prime}\right)$ imply that the predictions of the classical model of labor supply are consistent with the empirical findings of the Combined Experiment. Nevertheless, it is clear that the

lowers the significance of the wage effect to $p=.01$ (the sign of all other effects remained the same).

${ }^{37}$ It is possible that subjects react differently to a wage increase than to a wage decrease. To explore this possibility an equation similar to eq. (10), but which included a dummy variable that equaled one for those subjects that received a wage decrease, did not qualitatively alter any of the estimated coefficients with the exception of the coefficient on $F$ that, while still insignificant, had an estimated negative coefficient (still small in magnitude at -.30 ). The insignificance of the dummy variable leads us to reject the hypothesis that subjects respond differently (in terms of magnitude of change) when faced with a wage decrease.

${ }^{38}$ If we omit the data from day B, as was done with the Intensity Experiment data, the results are not appreciably altered. The hours of work equation is then estimated to be: $h=28.61+91.24$ wage $-.22 F$. The $p$-values of $\alpha, \beta_{1}$, and $\beta_{2}$ are, respectively, $.04, .00$, and .84 .

39 Oettinger (1998) also studies labor supply elasticities, but he focuses on the labor participation decision and finds a participation elasticity of about .60 for baseball stadium vendors. 
Table 5

Elasticities on $b$ and $b_{w}$ in the Combined and Intensity Experiments

\begin{tabular}{lcccc}
\hline & \multicolumn{2}{c}{$\begin{array}{c}\text { Intensity } \\
\text { Experiment }\end{array}$} & & \multicolumn{2}{c}{ Combined Experiment } \\
\cline { 2 - 3 } \cline { 5 - 5 } Specific Elasticity & Average Time & & Minutes Worked & Average Time* \\
\hline Compensated wage & -.10 & & .46 & -.02 \\
Total income & .01 & .01 & -.01 \\
Total wage & -.09 & .47 & -.03 \\
\hline
\end{tabular}

* These average paragraph production time elasticities for the Combined Experiment are from a simple random-effects model (favored over an OLS and fixed-effects specification by the Lagrange Multiplier and Hausman tests). Both wage and income effects were statistically insignificant, however, and these results should be interpreted with caution. The estimated model is AvrTime $=5.99-.55 w a g e-.04 F$. The $p$-values for $\alpha, \beta_{1}$, and $\beta_{2}$ are, respectively, $.00, .23$, and .20 .

wage response implied in equation $\left(10^{\prime}\right)$ does not reveal the full labor supply response of the workers. We also note that the predictions of the Combined Model are consistent with observed negative substitution effects on hours worked for several individuals. The same cannot be said of the classical model. These experimental results imply that on-the-job leisure (lower work effort) is not only significant enough to consume in a restricted experimental setting, but also that the hours of work choice significantly influences a worker's choice of effort. Most workers responded to a compensated wage increase in the Combined Experiment by decreasing work effort, yet in the Intensity Experiment these wage increases generally increased effort.

\section{Concluding Remarks}

A desirable feature of any theory is its ability to predict outcomes. The classical labor supply model has been widely implemented in empirical studies and has found, for the most part, support in the data. Its predictions are inconsistent, however, with a nontrivial number of empirically estimated negative substitution effects on hours of work. The Combined Model in this article extends the classical theory by allowing for a dual labor supply choice: hours of work and work effort. This Combined Model is consistent with empirically estimated negative substitution effects in the literature. Such negative substitution effects on hours worked can result when on- and off-the-job leisure are substitute goods. Furthermore, even when substitution effects on hours worked are positive, the Combined Model suggests that these effects are not the full representation of the workers' labor supply response.

This article also employs a distinctive approach for testing labor economic theories that complements the growing body of field data on piece rates and labor supply. We have used controlled laboratory experiments to observe subjects' homegrown preferences for labor and leisure. Such 
experiments are cost-effective real economic environments that are capable of generating data that do not exist in the field. The Combined Experiment provides sufficiently detailed data to test the Combined Model, and the results are consistent with the implications of the model. We find both positive and negative substitution effects on hours of work, with the "average" substitution effect being positive. Such results direct us to include measures of work effort as well as hours of work in our econometric models. While we know of no field data that provide both hours of work and effort information, estimated substitution effects based on only hours of work are an incomplete measure of the total response to a compensated wage change. Employers are presumably most interested in the total response when exploring the effects of a wage change on the firm's production.

In addition to the results of the Combined Experiment, the Intensity Experiment is also of interest because it recreates the fixed-hours environment of many short-run labor supply decisions. Compensated wage decreases significantly decrease average production times, which has important implications for human resource management. Specifically, more work effort can be elicited by giving income-compensated wage increases to employees. Such income compensations might involve reducing a worker's nonpecuniary compensation (health benefits, vacation time, etc.). The point is that employers may be able to elicit higher effort levels, while still holding overall compensation constant at a base effort level, by tying more of the compensation package to work effort.

\section{Appendix A}

\section{Derivation of Substitution and Income Effects in the Combined Model}

For simplicity we define the utility function in terms of three goods (consumption and the two leisure goods) instead of goods and "bads." The time and budget constraints allow us to translate the results from wage effects on leisure to wage effects and hours of work and work effort.

Let the utility function be quasi concave; twice continuously differentiable; and increasing in consumption $c$, off-the-job leisure $l$, and on-thejob leisure $b_{l}$. Therefore, we have $U=U\left(c, l, b_{l}\right)$ with $U_{c}>0, U_{l}>0$, $U_{b_{l}}>0$. For notational simplicity we henceforth refer to goods $c, l$, and $h_{l}$ as goods 1,2 , and 3 , respectively. Therefore, $U_{c}, U_{l}, U_{b_{l}}$ will be referred to as $U_{1}, U_{2}$, and $U_{3}$ (with similar numeric notation for higher order derivatives).

The constraints on behavior are the following: $w h_{w}+F=p c$ (the budget constraint), $b+l=T$ (the time constraint), and $b_{w}+b_{l}=b$ (the work time constraint), where $F$ is exogenous (nonwage) income, $w$ is the wage that is only paid per hour of productive labor, $T$ is total time available, and $b_{w}$ is productive hours spent at work. Notice that a given choice of $l$ and $b_{l}$ will define $b$ and $b_{w}$. We now normalize the price of the 
consumption good to $p=1$. The budget constraint can then be written as $w T-w l-w h_{l}+F-c=0$. It is important to realize from the time constraint that the wage effect on $b$ will just be the negative of the wage effect on $l$. The same cannot be said for $b_{w}$ and $b_{l}$ since the sign of $b_{w}$ is also dependent upon the choice of $b$, not just $b_{l}$.

The first-order conditions from the constrained maximization problem are:

$$
\begin{aligned}
U_{1}-\lambda & =0 \\
U_{2}-\lambda w & =0 \\
U_{3}-\lambda w & =0 \\
w T-w l-w b_{l}+F-c & =0 .
\end{aligned}
$$

From these we see that $U_{2} / U_{1}=w, U_{3} / U_{1}=w$, and $U_{3} / U_{2}=1$. For future reference, we also note that the quasi-concavity condition guarantees that the bordered determinant of the utility function behaves as follows:

$$
\begin{gathered}
|B|=\left|B_{3}\right|=\left|\begin{array}{cccc}
0 & U_{1} & U_{2} & U_{3} \\
U_{1} & U_{11} & U_{12} & U_{13} \\
U_{2} & U_{21} & U_{22} & U_{23} \\
U_{3} & U_{31} & U_{32} & U_{33}
\end{array}\right|<0 \\
\left|B_{2}\right|=\left|\begin{array}{ccc}
0 & U_{1} & U_{2} \\
U_{1} & U_{11} & U_{12} \\
U_{2} & U_{21} & U_{22}
\end{array}\right|>0 \quad\left|B_{1}\right|=\left|\begin{array}{cc}
0 & U_{1} \\
U_{1} & U_{11}
\end{array}\right|<0 .
\end{gathered}
$$

In particular, from the conditions on the first and second principal minors, together with symmetry conditions, we have

$$
\begin{aligned}
& 2 U_{1} U_{2} U_{12}-U_{1}^{2} U_{22}-U_{2}^{2} U_{11}>0 \\
& 2 U_{1} U_{3} U_{13}-U_{1}^{2} U_{33}-U_{3}^{2} U_{11}>0 \\
& 2 U_{2} U_{3} U_{23}-U_{2}^{2} U_{33}-U_{3}^{2} U_{22}>0,
\end{aligned}
$$

and also $U_{11}<0, U_{22}<0, U_{33}<0$. By using the first-order conditions, the first three equations in equation (A3) reduce to

$$
\begin{aligned}
2 w U_{12}-U_{22}-w^{2} U_{11} & >0 \\
2 w U_{13}-U_{33}-w^{2} U_{11} & >0 \\
2 U_{23}-U_{33}-U_{22} & >0 .
\end{aligned}
$$


Now, given the equation system defined in equation (A1), if partial derivatives are all continuous with respect to all the endogenous variables $\left(\lambda, c, l\right.$, and $\left.h_{l}\right)$ and exogenous variables $(w$ and $F)$, and if the Jacobian determinant of the system of equations in (A1) is nonzero, then there exists a neighborhood in which equation (A1) defines a set of implicit functions for the maximands:

$$
\begin{aligned}
\bar{b}_{l} & =\bar{b}_{l}(w, F) \\
\bar{c} & =\bar{c}(w, F) \\
\bar{l} & =\bar{l}(w, F) \\
\bar{\lambda} & =\bar{\lambda}(w, F)
\end{aligned}
$$

(we will subsequently drop the bar notation for the optimal values of each choice variable). The condition on the Jacobian determinant is guaranteed to be satisfied, however, since we note that

$$
|J|=\left|\begin{array}{cccc}
0 & -1 & -w & -w \\
-1 & U_{11} & U_{12} & U_{13} \\
-w & U_{21} & U_{22} & U_{23} \\
-w & U_{31} & U_{32} & U_{33}
\end{array}\right|=|\bar{H}|
$$

(the bordered Hessian of the constrained problem).

Second-order conditions for utility maximization imply that $|\bar{H}|<0$ and so we know that the Jacobian determinant is nonzero, the conditions of the Implicit Function Theorem are satisfied, and this gives each equation of (A1) the status of identity in the neighborhood of interest. It also guarantees that the implicit functions defined in equation (A4) are continuous and have continuous partial derivatives with respect to the exogenous variables $w$ and $F$.

\section{The Comparative Static Analysis}

Next, we totally differentiate each equation in (A1) and arrange to get

$$
\begin{aligned}
-d \lambda+U_{11} d c+U_{12} d l+U_{13} d b_{l} & =0 \\
-w d \lambda+U_{21} d c+U_{22} d l+U_{23} d b_{l} & =\lambda d w \\
-w d \lambda+U_{31} d c+U_{32} d l+U_{33} d b_{l} & =\lambda d w-d c-w d l-w d b_{l} \\
& =l d w+b_{l} d w-d F-T d w .
\end{aligned}
$$

Notice that the right-hand side of the last equation in (A6) can be written instead as $-d c-w d l-w d h_{l}=-b_{w} d w-d F$. We first find the 
income effect by setting $d w=0$ in equation (A6), dividing each equation through by $d F$ and interpreting the ratios of differentials as partial derivatives. The result is

$$
\begin{aligned}
\frac{-\partial \lambda}{\partial F}+U_{11} \frac{\partial c}{\partial F}+U_{12} \frac{\partial l}{\partial F}+U_{13} \frac{\partial h_{l}}{\partial F} & =0 \\
-w \frac{\partial \lambda}{\partial F}+U_{21} \frac{\partial c}{\partial F}+U_{22} \frac{\partial l}{\partial F}+U_{23} \frac{\partial h_{l}}{\partial F} & =0 \\
-w \frac{\partial \lambda}{\partial F}+U_{13} \frac{\partial c}{\partial F}+U_{32} \frac{\partial l}{\partial F}+U_{33} \frac{\partial h_{l}}{\partial F} & =0 \\
\frac{-\partial c}{\partial F}-w \frac{\partial l}{\partial F}-w \frac{\partial h_{l}}{\partial F} & =-1 .
\end{aligned}
$$

Or, in matrix form,

$$
\left[\begin{array}{cccc}
0 & -1 & -w & -w \\
-1 & U_{11} & U_{12} & U_{13} \\
-w & U_{21} & U_{22} & U_{23} \\
-w & U_{31} & U_{32} & U_{33}
\end{array}\right]\left[\begin{array}{c}
\partial \lambda / \partial F \\
\partial c / \partial F \\
\partial l / \partial F \\
\partial b_{l} / \partial F
\end{array}\right]=\left[\begin{array}{c}
-1 \\
0 \\
0 \\
0
\end{array}\right] .
$$

Here, the $4 \times 4$ matrix is the bordered Hessian, whose determinant is identical to the determinant of the Jacobian matrix J. Now, confining our attention to the two variables of interest $\left(l\right.$ and $\left.h_{l}\right)$, we can use Cramer's rule to find the two income effects

$$
\frac{\partial l}{\partial F}=\frac{-1}{|J|}\left|\begin{array}{ccc}
-1 & U_{11} & U_{13} \\
-w & U_{12} & U_{23} \\
-w & U_{31} & U_{33}
\end{array}\right| \quad \text { and } \quad \frac{\partial h_{l}}{\partial F}=\frac{1}{|J|}\left|\begin{array}{ccc}
-1 & U_{11} & U_{12} \\
-w & U_{12} & U_{22} \\
-w & U_{31} & U_{32}
\end{array}\right| .
$$

Next, we find the effect of an uncompensated wage change by setting $d F$ $=0$ and dividing equation (A6) through by $d w$ to yield the matrix equation

$$
\left[\begin{array}{cccc}
0 & -1 & -w & -w \\
-1 & U_{11} & U_{12} & U_{13} \\
-w & U_{21} & U_{22} & U_{23} \\
-w & U_{31} & U_{32} & U_{33}
\end{array}\right]\left[\begin{array}{c}
\partial \lambda / \partial w \\
\partial c / \partial w \\
\partial l / \partial w \\
\partial b_{l} / \partial w
\end{array}\right]=\left[\begin{array}{c}
-b_{w} \\
0 \\
\lambda \\
\lambda
\end{array}\right]
$$

From this, the two partial derivatives of interest emerge 


$$
\begin{aligned}
\frac{\partial l}{\partial w}= & \frac{\lambda}{|J|}\left|\begin{array}{ccc}
0 & -1 & -w \\
-1 & U_{11} & U_{13} \\
-w & U_{31} & U_{33}
\end{array}\right|-\frac{\lambda}{|J|}\left|\begin{array}{ccc}
0 & -1 & -w \\
-1 & U_{11} & U_{13} \\
-w & U_{21} & U_{23}
\end{array}\right| \\
& -\frac{h_{w}}{|J|}\left|\begin{array}{ccc}
-1 & U_{11} & U_{13} \\
-w & U_{21} & U_{23} \\
-w & U_{31} & U_{33}
\end{array}\right| \\
= & T_{1}+T_{2}+T_{3} \\
\frac{\partial b_{l}}{\partial w=} & \frac{-\lambda}{|J|}\left|\begin{array}{ccc}
0 & -1 & -w \\
-1 & U_{11} & U_{12} \\
-w & U_{31} & U_{32}
\end{array}\right|+\frac{\lambda}{|J|}\left|\begin{array}{ccc}
0 & -1 & -w \\
-1 & U_{11} & U_{12} \\
-w & U_{21} & U_{22}
\end{array}\right| \\
& +\frac{h_{w}}{|J|}\left|\begin{array}{ccc}
-1 & U_{11} & U_{12} \\
-w & U_{21} & U_{22} \\
-w & U_{31} & U_{32}
\end{array}\right| \\
= & T_{4}+T_{5}+T_{6} .
\end{aligned}
$$

From equations (A10) and (A11) we can refer to the $T_{i}$ terms to simplify our analysis of these uncompensated wage effects.

Notice that from equations (A8) we can write $T_{3}$ and $T_{6}$ as $h_{w}(\partial l / \partial F)$ and $h_{w}\left(\partial h_{l} / \partial F\right)$, respectively. Therefore, $T_{3}$ and $T_{6}$ are the income effects for $l$ and $b_{l}$.

Next, in order to see how an income-compensated substitution effect is reflected in equations (A10) and (A11), notice that by holding $d F=0$ we can rewrite the constraint equation from (A6) as

$$
-d c-w d l-w d b_{l}=-b_{w} d w .
$$

Since the effectual change in income that the worker experiences is then $b_{w} d w$, we compensate the consumer by setting $b_{w}=0$ when changing the wage. As such, the vector of constants from equation (A9) is now $\left[\begin{array}{llll}0 & 0 & \lambda & \lambda\end{array}\right]^{\prime}$ instead of $\left[\begin{array}{llll}-b_{w} & 0 & \lambda & \lambda\end{array}\right]^{\prime}$. Given this new vector of constants we now can find the income-compensated wage effects on $l$ and $b_{w}$.

$$
\begin{aligned}
\left.\left(\frac{\partial l}{\partial w}\right)\right|_{\text {income compensated }} & =\frac{\lambda}{|J|}\left|\begin{array}{ccc}
0 & -1 & -w \\
-1 & U_{11} & U_{13} \\
-w & U_{31} & U_{33}
\end{array}\right|-\frac{\lambda}{|J|}\left|\begin{array}{ccc}
0 & -1 & -w \\
-1 & U_{11} & U_{13} \\
-w & U_{21} & U_{23}
\end{array}\right| \\
& =T_{1}+T_{2}
\end{aligned}
$$




$$
\begin{aligned}
\left.\left(\frac{\partial h_{l}}{\partial w}\right)\right|_{\text {income compensated }} & =\frac{-\lambda}{|J|}\left|\begin{array}{ccc}
0 & -1 & -w \\
-1 & U_{11} & U_{12} \\
-w & U_{31} & U_{32}
\end{array}\right|+\frac{\lambda}{|J|}\left|\begin{array}{ccc}
0 & -1 & -w \\
-1 & U_{11} & U_{12} \\
-w & U_{21} & U_{22}
\end{array}\right| \\
& =T_{4}+T_{5} .
\end{aligned}
$$

And so, as usual, we can write the uncompensated wage effects as a combination of a substitution and an income effect

$$
\begin{aligned}
& \frac{\partial l}{\partial w}=\left.\left(\frac{\partial l}{\partial w}\right)\right|_{\text {income compensated }}+b_{w} \frac{\partial l}{\partial F} \quad \text { and } \\
& \frac{\partial h_{l}}{\partial w}=\left.\left(\frac{\partial h_{l}}{\partial w}\right)\right|_{\text {income compensated }}+b_{w} \frac{\partial h_{l}}{\partial F} .
\end{aligned}
$$

In general, the income effects have no theoretical sign, but usually we would predict that these substitution effects be theoretically negative. In the combined model, however, we cannot theoretically sign the substitution effect, either.

\section{Determining the Sign of the Combined Substitution Effect}

To see that the combined model can produce theoretically negative substitution effects on hours of work (which corresponds here to showing that we can have theoretically positive substitution effects on hours of leisure), let us expand the substitution effect terms in equations (A12) and (A13) to get

$$
\begin{aligned}
\left.\left(\frac{\partial l}{\partial w}\right)\right|_{\text {income compensated }}= & \frac{\lambda}{|J|}\left|\begin{array}{ccc}
0 & -1 & -w \\
-1 & U_{11} & U_{13} \\
-w & U_{31} & U_{33}
\end{array}\right|-\frac{\lambda}{|J|}\left|\begin{array}{ccc}
0 & -1 & -w \\
-1 & U_{11} & U_{13} \\
-w & U_{21} & U_{23}
\end{array}\right| \\
= & \frac{\lambda}{|J|}\left[w U_{31}-U_{33}+w U_{13}-w^{2} U_{11}\right] \\
& -\frac{\lambda}{|J|}\left[w U_{21}-U_{23}+w U_{13}-w^{2} U_{11}\right] \quad(\mathrm{A} 15) \\
\left.\left(\frac{\partial b_{l}}{\partial w}\right)\right|_{\text {income compensated }}= & \frac{-\lambda}{|J|}\left|\begin{array}{ccc}
0 & -1 & -w \\
-1 & U_{11} & U_{12} \\
-w & U_{31} & U_{32}
\end{array}\right|+\frac{\lambda}{|J|}\left|\begin{array}{ccc}
0 & -1 & -w \\
-1 & U_{11} & U_{12} \\
-w & U_{21} & U_{22}
\end{array}\right| \\
= & \frac{\lambda}{|J|}\left[w U_{21}-U_{22}+w U_{12}-w^{2} U_{11}\right] \\
& -\frac{\lambda}{|J|}\left[w U_{31}-U_{32}+w U_{12}-w^{2} U_{11}\right] .
\end{aligned}
$$


Notice that the first term in both equations (A15) and (A16) is guaranteed to be negative given equation $\left(\mathrm{A} 3^{\prime}\right)$ that followed from quasi concavity, and the fact that we know the Jacobian determinant to be negative. This should not be surprising since these terms represent the standard substitution effect in each case. The sign of the additional term will depend on some theoretical assumptions. In rewriting equations (A15) and (A16) once again, we have

$$
\begin{aligned}
\left.\left(\frac{\partial l}{\partial w}\right)\right|_{\text {income compensated }}=\left\{\left.\left(\frac{\partial l}{\partial w}\right)\right|_{\text {income compensated }} ^{*}\right. \\
\\
+\frac{\lambda}{|J|}\left[w^{2} U_{11}+U_{32}-w\left(U_{31}+U_{12}\right)\right],
\end{aligned}
$$

where

$$
\left.\left(\frac{\partial l}{\partial w}\right)\right|_{\text {income compensated }} ^{*}
$$

would be the usual (negatively signed) substitution effect on $l$.

$$
\begin{aligned}
\left.\left(\frac{\partial h_{l}}{\partial w}\right)\right|_{\text {income compensated }}= & {\left[\left.\left(\frac{\partial h_{l}}{\partial w}\right)\right|_{\text {income compensated }} ^{*}\right.} \\
& +\frac{\lambda}{|J|}\left[w^{2} U_{11}+U_{23}-w\left(U_{21}+U_{13}\right)\right],
\end{aligned}
$$

where

$$
\left.\left(\frac{\partial h_{l}}{\partial w}\right)\right|_{\text {income compensated }} ^{*}
$$

would be the usual (negatively signed) substitution effect on $b_{l}$.

Notice the symmetry in equations (A17) and (A18). It is obvious from the possible combinations of signs in the second portion of the substitution effect that this portion could be positive and, if stronger than the negative portion of the substitution effect, could create an overall positive substitution effect on $l$ or $b_{l}$. Given the time constraint, a positive substitution effect on $l$ would correspond directly to a negative substitution effect on $b$. The assumptions necessary for this to occur are discussed in Section II of the article. 


\section{References}

Altonji, Joseph G., and Paxson, Christina H. "Job Characteristics and Hours of Work." In Research in Labor Economics, edited by Ronald G. Ehrenberg, 8, pt. A: 1-55. Greenwich, CT: JAI Press, 1986.

Ang, James S., and Schwarz, Thomas. "Risk Aversion and Information Structure: An Experimental Study of Price Variability in the Securities Markets." Journal of Finance 40 (July 1985): 825-44.

Ashenfelter, Orley. "Unemployment as Disequilibrium in a Model of Aggregate Labor Supply." Econometrica 48 (April 1980): 547-64.

Atkinson, A. B., and Stern, N. H. "On the Switch from Direct to Indirect Taxation." Journal of Public Economics 14 (October 1980): 195-224.

Battalio, Raymond C.; Green, Leonard.; and Kagel, John H. "IncomeLeisure Tradeoffs of Animal Workers." American Economic Review 71 (September 1981): 621-32.

Battalio, Raymond C.; Kagel, John H.; Rachlin, Howard; and Green, Leonard. "Commodity-Choice Behavior with Pigeons as Subjects." Journal of Political Economy 89 (February 1981): 67-91.

Becker, Gary S. "A Theory of the Allocation of Time." Economic Journal 75 (September 1965): 493-517.

Bickel, W.; DeGrandpre, R.; Highes, J.; and Higgins, S. "Behavioral Economics of Drug Self-Administration II: A Unit-Price Analysis of Cigarette Smoking." Journal of the Experimental Analysis of Bebavior 55 (1991): 145-54.

Bigelow, G., and Liebson, J. "Cost Factors Controlling Alcoholic Drinking." Behavioral Record 22 (1972): 305-14.

Camerer, Colin; Babcock, Linda; Loewenstein, George; and Thaler, Richard. "Labor Supply of New York City Cab Drivers: One Day at a Time." Quarterly Journal of Economics 112 (May 1997): 407-41.

Collier, G.; Hirsch, E.; and Hamlin, P. "The Ecological Determinants of a Reinforcement in the Rat." Physiology and Behavior 9 (1972): 705-16.

Collier, G., and Jennings, W. "Work as a Determinant of Instrumental Performance." Journal of Comparative and Physiological Psychology 68 (1969): 659-62.

Cox, James C., and Epstein, Seth. "Preference Reversals without the Independence Axiom." American Economic Review 79 (June 1989): 408-26.

Davis, Douglas D., and Holt, Charles A. Experimental Economics. Princeton, NJ: Princeton University Press, 1993.

Ham, John C. "Estimation of a Labor Supply Model with Censoring due to Unemployment and Underemployment." Review of Economic Studies 49 (July 1982): 335-54.

Killingsworth, Mark R., and Heckman, James J. "Female Labor Supply: A Survey." In The Handbook of Labor Economics, edited by Orley Ashenfelter and Richard Layard, pp. 103-204. Amsterdam: Elsevier Science Publishers, 1986.

Lazear, Edward P. “Agency, Earnings Profiles, Productivity, and Hours Restrictions." American Economic Review 71 (September 1981): 606-20.

- "Performance Pay and Productivity." Unpublished manuscript. 
Stanford, CA: Stanford University, Hoover Institution and Graduate School of Business, 1998.

Lewis, H. Gregg. "Hours of Work and Hours of Leisure." In Industrial Relations Research Association, Proceedings of the Ninth Annual Meeting, 1957. Reprinted in Readings in Labor Market Analysis, edited by L. Reed Tripp, 1971.

Meisch, R., and Thompson, T. "Determinants of Ethanol Intake in Rats: Food Intake and Ethanol Concentration." Reports from the Research Laboratories no. PR-72-3. University of Minnesota, Department of Psychiatry, 1972.

- "Ethanol as a Reinforcer: Effects of Fixed-Ratio Size and Food Deprivation." Psychopharmacologia (Berlin) 28 (1973): 171-83.

Moffitt, R., and Kenhrer, K. "The Effect of Tax and Transfer Programs on Labor Supply: The Evidence from the Income Maintenance Experiments." Research in Labor Economics, edited by Ronald G. Ehrenberg, 4:103-50. Greenwich, CT: JAI Press, 1981.

Nakamura, Alice, and Nakamura, Masao. "A Comparison of the Labor Force Behavior of Married Women in the United States and Canada, with Special Attention to the Impact of Income Taxes." Econometrica 49 (March 1981): 451-90.

Oettinger, Gerald S. "An Empirical Analysis of the Daily Labor Supply of Stadium Vendors." Unpublished manuscript. University of Texas, Department of Economics, 1998.

Paarsch, Harry J., and Shearer, Bruce. "Piece Rates, Fixed Wages, and Incentive Effects: Statistical Evidence from Payroll Records." Unpublished manuscript. 1998. (a)

_.. "Work Schedules, Worker Fatigue, and Intertemporal Productivity: A Comparison of Fixed Wages to Piece Rates." Unpublished manuscript. 1998. (b)

Pencavel, John. "Labor Supply of Men: A Survey." In The Handbook of Labor Economics, edited by Orley Ashenfelter and Richard Layard, pp. 3-102. Amsterdam: Elsevier Science Publishers, 1986.

- "Work Effort, On-the-Job Screening, and Alternative Methods of Remuneration." In Research in Labor Economics, edited by Ronald G. Ehrenberg, 1:225-58. Greenwich, CT: JAI Press, 1977.

Robbins, L. "On the Elasticity of Demand for Income with Respect to Effort." Econometrica 10 (1930): 123-29.

Robins, Philip K. "A Comparison of the Labor Supply Findings from the Four Negative Income Tax Experiments." Journal of Human Resources 20 (Fall 1985): 567-82.

Robinson, Chris, and Tomes, Nigel. "More on the Labour Supply of Canadian Women." Canadian Journal of Economics 18 (February 1985): 156-63.

Spiegelman, Robert G., and Yaeger, K. E. "The Seattle and Denver Income Maintenance Experiments: Overview." Journal of Human Resources 15 (Fall 1980): 463-79.

Yellen, Janet L. "Efficiency Wage Models of Unemployment." American Economic Review: Papers and Proceedings 74 (May 1984): 200-05. 
Copyright of Journal of Labor Economics is the property of University of Chicago Press. The copyright in an individual article may be maintained by the author in certain cases. Content may not be copied or emailed to multiple sites or posted to a listserv without the copyright holder's express written permission. However, users may print, download, or email articles for individual use. 